\title{
Beyond Expectations: Autonomy and the Iranian Postgraduate Students in Malaysian Public Universities
}

Sina Neissi, Habsah Hussin*

Department of Language Education \& Humanities; Faculty of Educational Studies, Universiti Putra Malaysia, 43400 Serdang Selangor, Malaysia

Corresponding Author: Habsah Hussin, E-mail: drhhesr@gmail.com

\section{ARTICLE INFO}

Article history

Received: June 12, 2017

Accepted: August 27, 2017

Published: December 01, 2017

Volume: 6 Issue: 7

Special Issue on Language \& Literature

Advance access: September 2017

Conflicts of interest: Non

Funding: None

\begin{abstract}
Iranian learners at all levels of education (primary, secondary and tertiary) face a number of constraints in their studies due to restriction of educational system, cultures, upbringing and expectations of society. Based on this premise the researchers would like to explore the degrees of autonomy as practiced by selected Iranian postgraduate students studying at three premier public universities in Malaysia. Data were gathered using the Learner Autonomy Profil (LAP) developed by Confessore \& Confessore (1992). The findings reveal that these Iranian postgraduate students do practice autonomy and know how to apply positive coping strategies in their studies; thus indicating positive contradiction from the normal expectations of Iranian learners' performance in relation to autonomy. The paper concludes with the impacts and implications of the findings.
\end{abstract}

Key words: Autonomy, Iranian Postgraduate Students, Malaysian Public Universities, Learner Autonomy Profil (LAP)

\section{INTRODUCTION}

One of the much discussed issues in educational context worldwide is the role of autonomy in enhancing learners learning experiences and academic performance (Derrick \& Carr, 2003; Scharle and Szabó, 2000; Suharmanto, 2003). Its importance has made it to be seen as a global educational goal, especially in higher education settings (Aoki \& Smith, 1999; Benson \& Huang, 2008; Ponton \& Hall, 2003; Crome et al., 2011).

To understand the craze about this phenomenon, we need to know what learner autonomy is all about. The classic definition of learner autonomy as postulated by Holec (1981) is "the ability to take charge of one's own learning" (p. 9). To elaborate, learner autonomy involves learners in holistic learning in which they have choice of learning situations and are encouraged to express ideas (Kenny, 1993). Learners have the capacity of making decisions and implementing these decisions without the supervision of teachers or institutions (Dickinson, 1987). Although the high degree of freedom is not absolute, learners do not learn in isolation. In fact, they are actively involved in the learning process (Dickinson, 1992; Little, 1991). Littlewood (1996) postulates further that the degrees learners are autonomous depend on their ability and willingness to execute choices governing their actions. These scholars on autonomy are unanimous in saying that common features for autonomy are the concept of responsibility for own learning, having a certain degree of indepen- dence and autonomy as a process (Holec, 1981; Dickinson, 1987; Kenny, 1993; Dickinson, 1992; Little, 1991; Cotterall, 1995; Littlewood; 1996).

Despite the popularity of learner autonomy in the western context (Benson, 2007), learner autonomy has not made much progress in Iran. This could be due to several factors such as the existing education system in Iran, the culture, learners' upbringing at home and expectations of society. To elaborate, the traditional education system based on teacher-centred and rote learning approach still practiced in Iran (Naji Meidani \& Pishghadam, 2012; Karimnia, 2013) in (Sedigheh Shakib Kotamjani \& Habsah Hussin, 2017) deny teachers the opportunity to help their learners to be autonomous i.e. to have some degree of independence in making choices and expressing ideas and opinions (Dickinson, 1987; Little, 1991; Kenny, 1993). Teachers are not to be blamed because they have to collude with the requirement of the education system i.e. their accountability in education is measured via the effectiveness of their teaching in terms of their students' academic performance (Benson, 2001). This type of education system deprives learners not only of quality education but also succeeds only in producing passive learners who are acquiescence of whatever knowledge given by their teachers without questioning.

Another constraint for learner autonomy to thrive in Iran could be due to the fact that it is culturally dependent (Riley, 1988; Little, 2000; Smith, 2008) which means that adopting a western style autonomy (the popular form of autonomy) 
into a non-western setting (in this case, Iran) may not be appropriate (Smith, 2003) to yield the desired results (Iranian learners to become autonomous in their learning). Similarly, the conservative upbringing and close parental supervision at home (Littlewood, 1999); and expectations that these learners should adhere closely to the requirement of the education system, home upbringing and societal expectations have made these students not being able to be autonomous in their learning. In the long run, if these four factors are not properly addressed, they would adversely affect Iranian learners, especially for those who aspire to read their graduate studies at universities abroad.

As most of these foreign universities have made autonomy part of their university curriculum, it is imperative for the Iranian postgraduate students to have some degree of autonomy in their learning to ensure their academic survival and success in their studies (Dam, 1995; Legenhausen, 1999; Legenhausen, 2003; Deng, 2004). Studying in a foreign country will make it necessary for them to be self-reliance, independent and to be responsible for their own learning (Dickinson, 1987; Little, 1991; Little, 1999; Mahdavinia \& Nabatchi Ahmadi, 2011). In other words, they should have inculcated the attributes of autonomous learners.

Based on the constraints they have educationally (non-English speaking background; traditional education system; and no training in autonomy); conservative upbringing and cultures; and societal expectations; these learners were expected to face difficulty in pursuing their studies and coping with a new culture and context abroad (Robertson et al., 2000; Bayley et al., 2002; Borland and Pearce, 2002). To elaborate, postgraduate studies involve conducting research and reporting the research in the form of a thesis written in English. Researching and writing a doctoral thesis necessitate students to be skilled in self-management, conducting research, writing academically (Mulligan \& Kirkpatrick, 2000; Hellsten, 2002; Wong, 2004; Hellsten \& Prescott, 2004) and equipped with the appropriate interpersonal skills to interact effectively with a supervisor and fellow postgraduates of various nationalities.

The internationalization of higher education in recent years has resulted in a significant increase in the Iranian postgraduate population pursuing their doctoral degrees at public universities in Malaysia. Based on the constraints Iranian postgraduate students face in relation to autonomy in learning, the researchers would like to know how they would cope with the demands of their studies in Malaysia. The challenges would be greater as they have to cope with these mammoth tasks: i) they would be coming from an EFL (English as a Foreign Language) context (i.e. Iran) into an ESL (English as a Second Language) context (i.e. Malaysia); ii) they would be studying at three premier public research universities in Malaysia; in which all three universities have embedded autonomy in learning into their curriculum. Again, would Iranian postgraduate students pursuing their doctoral degrees at these three Malaysian universities have issues in their studies given the disparity in their context and educational backgrounds and expectations? To answer these questions, this paper will focus its objective on investigating whether these Iranian post graduate students studying in foreign universities abroad (i.e. in Malaysia) do practice autonomy and apply positive coping strategies in their learning.

\section{THE ACTUAL STUDY}

Participants of the study were obtained by enlisting the assistance of the Iranian Consulate in Malaysia, who provided the list and contact details of Iranian postgraduate students studying at three research public universities located in the Klang valley, Malaysia; i.e. Universiti Putra Malaysia (UPM), Universiti Teknologi Malaysia (UTM) and Universiti Kebangsaan Malaysia (UKM). 227 Iranian postgraduate students studying at these three universities, selected through a multi stage cluster random sampling design, participated in the study. Learner Autonomy Profile (LAP) survey developed by Confessore \& Confessore (1992) was used as the instrument of the study. The participants were provided with a detailed guideline (in Farsi - their first language) on how to complete the LAP online. They completed inputting the data into LAP within two weeks.

\section{FINDINGS AND DISCUSSION}

Data in Table 1 illustrate the 227 participants' scores in learner autonomy. Comparing the mean of LAP total scores (485.86) with the highest possible score in the LAP (660) reveal that these Iranian postgraduate students have a high level of autonomy in their learning. This result is in contradiction with the findings of previous research on autonomy conducted by Iranian scholars with Iranian learners in the Iranian context. To elaborate, findings of Ahmadi \& Mahdavi-Zafarghandi's (2013) research with law major undergraduates in Iran conform to the popular beliefs that Iranian learners are passive, heavily dependent on their teachers and tried to escape any involvement in autonomous activities. Farahani's (2014) study conducted with Iranian EFL college learners yielded the result that these college learners did not exhibit autonomous learning behaviour. Similarly, Hashemian \& Sourehjani's (2011) research to investigate the relationship between motivation, autonomy and academic performance of Iranian university students in Iran failed to establish any relationship among the three entities.

There are a number of reasons for the participants of this study to acquire a certain degree of autonomy in their learning, thus making the finding of this study to be different from previous and existing research conducted with Iranian learners on autonomy. One reason is that they are away from the binding constraints (traditional education system, conservative upbringing and cultures, and societal expectations) of their local context; and the exposure and immersion in a learning environment that nurture autonomy as a style

Table 1. Total LAP (short form) mean scores

\begin{tabular}{lccccc}
\hline Variables & $\begin{array}{c}\text { Highest } \\
\text { possible }\end{array}$ & Min & Max & $\begin{array}{c}\text { Mean } \\
(\mathbf{n = 2 2 7})\end{array}$ & SD \\
\hline Total LAP & 660 & 233.5 & 630.75 & 485.86 & 79.93 \\
\hline
\end{tabular}


of learning have enable these Iranian postgraduate students to break free from the constraining shackles and thus able to thrive in their new found freedom (to a certain extent) of expressions and actions. In contrast, the three studies by Hashemian \& Sourehjani (2011), Ahmadi \& Mahdavi-Zafarghandi (2013), and Farahani (2014) mentioned earlier failed to produce positive results because the three studies were conducted locally (in Iran) thus still being influenced by the four constraining factors. This finding too concurs with Park's (2003) finding that the level of learner autonomy of Asian learners studying abroad was significantly higher than those studying in their own country.

Maturity of the participants may have been another determining factor for the results. While the participants of the three research projects conducted in Iran were undergraduates or college students, the participants of this study were all Iranian postgraduate students. The rigour of postgraduate studies such as the need to be independent, resourceful, adapting to the demands and challenges of their new context (Malaysia) and the new learning environment (the three public universities) has necessitated these Iranian postgraduates to be versatile and rise above the challenges to acquire autonomy. This is in accordance with Knowles' (1984) view that learners develop autonomy when they are faced with challenges to integrate and by their use of their talents independently and by developing initiative for planning and evaluation of their development. In this sense, the participants of this study have demonstrated "functional learner autonomy" (Confessore \& Park, 2004) when they were able to select and participate in learning projects (their doctoral theses) in which they may function independently (in doing the theses individually) or in concert with others (collaborating with peers, consulting with supervisory team, getting information from reading the works of other scholars). By making efficient and appropriate use of personal resources and the resources of others (Confessore \& Park, 2004) too; these Iranian postgraduate learners have succeeded in showcasing their ability to apply positive coping strategies and willingness to take responsibility for their own learning.

Additionally, the finding of this study has also proven that successful acquisition of autonomy depends on individual characteristics of the learners (Littlewood, 2001; Gieve \& Clark, 2005) regardless of their socio-cultural backgrounds.

The positive finding points to the fact that given the opportunity and possibly proper exposure to a conducive environment for autonomy, Iranian postgraduate learners would be able to apply a degree of autonomy and demonstrate positive coping strategies in their learning. Therefore, this finding could be used to create awareness for those with authority in education in Iran to consider integrating autonomy into the country's curriculum, to enable the Iranian education system to be modernized, to keep pace with changing times and to cater to the Iranian learners' needs. However, the learner autonomy that is currently being practiced worldwide is deeply entrenched in western cultural values (Riley, 1988; Pennycook, 1997) and this might be rejected by the Iranian authority on education. Hence, for autonomy to be acceptable in the Iranian educational context, the autonomy to be incorporated into the Iranian curriculum should cater and accommodate to the Iranian social, cultural and societal values. Conversely, if the Iranian education authority is still in denial of the benefits of autonomy for Iranian learners and thus not doing anything to improve the situation by incorporating autonomy into the Iranian education curriculum, the Iranian learners would be deprived of developing their full potentials which in the long run would be a great loss for Iran in terms of human capital.

\section{CONCLUSION}

The finding that Iranian postgraduate students could be autonomous and have positive coping strategies while studying abroad, is beyond what is expected of them, given the constraints they face in the country's educational context. To incorporate autonomy into the Iranian curriculum would require concerted effort on all the parties involved. Progress may still be slow but it will be a step in the right direction.

\section{Researchers' Notes}

Although LAP is integral as the instrument of the actual research, LAP is mentioned only in passing here because this paper discusses only two issues from the research i.e. the practice of autonomy and application of positive coping strategies by Iranian postgraduate students in their learning.

\section{REFERENCES}

Ahmadi, R. \& Mahdavi-Zafarghandi, A. (2013). Autonomous language learning in Iranian context: To what extent do students take responsibility for their learning?. International Journal of Research Studies in Language Learning, 2(5): 17-26.

Aoki, N., \& Smith, R.C. (1999). Learner autonomy in cultural context: The case of Japan. In Cotterall \& D. Crabbe (eds.), Learner autonomy in language leanring: Defi ing the field and affecting change (pp.19-27). Franfurtam-Main: Peter Lang.

Bayley, S., Fearnside, R., Arnol, J., Misiano, J. and Rottura, R. (2002) International students in Victoria. People and Place, 10, (2), 45-54.

Benson, P. (2001). Teaching and researching autonomy in language learning. London: Longman.

Benson, P. (Ed.). (2007). Learner autonomy 8: Teacher and learner perspectives. Dublin, Ireland: Authentik.

Benson, P., \& Huang, J. (2008). Autonomy in the transition from foreign language learning to foreign language teaching. D.E.L.T.A., 24 (esp.), 421-439.

Borland, $\mathrm{H}$ and Pearce, A. (2002) Identifying key dimensions of language and cultural disadvantage at university. Australian Review of Applied Linguistics, 25, (2), 101127.

Confessore, G. J, Confessore, S. J, (1992) In search of consensus in the study of self-directed learning. In: Long, H B and Associates 1992 Self-directed Learning: Application and research. Oklahoma Research Center for Continuing Professional and Higher Education, Univer- 
sity of Oklahoma, Norman, Oklahoma Craik, G L 1840 Pursuit of Knowledge Under Difficulties: Its Pleasures and Rewards. Harper \& Brothers, New York

Confessore, G. J. \& Park, E. (2004). Factor validation of the Learner Autonomy Profile, version 3.0 and extraction of the short form. International Journal of Self-directed Learning, 1 (1), 39 -58.

Cotterall, S. (1995). Developing a course strategy for learner autonomy. ELT Journal, 49(3), 219-227.

Crome, K., Farrar, R., \& O'Connor, P. (2011). What is Autonomous Learning. Discourse, 9(1), 111-126. Retrieved from http://prs.heacademy.ac.uk/view.html/PrsDiscourse Articles/113.

Dam, L. (1995). Learner Autonomy 3: from Theory to Classroom Practice. Dublin: Authentik.

Deng, L.(2004). Cultivating foreign language learners' autonomous learning. Journal of Sichuan Foreign Language University2, 156-159.

Derrick, M. G. \& Carr, P. B. (2003). Facilitating and understanding autonomy in adult learners. New Horizons in Adult Education, 17(2), 4-10.

Dickinson, L. (1987). Self-instruction in language learning. Cambridge: Cambridge University press.

Dickinson, L. (1992). Learner Autonomy 2: Learner Training for LanguageLearning. Dublin: Authentik.

Farahani, M. (2014). From Spoon Feeding to Self-Feeding: Are Iranian EFL Learners Ready to Take Charge of their Own Learning? Electronic Journal of Foreign Language Teaching, 11(1), 98-115.

Gieve, S. \& R. Clark (2005). 'The chinese approach to learning': Cultural trait or situated response? The case of a self-directed learning programme. System 33.2, 261-276.

Hashemian, M. \& Soureshjani, K. H. (2011). The interrelationship of autonomy, motivation, and academic performance of Persian L2 learners in distance education contexts. Theory and Practice in Language Studies, 1(4), 319-326

Hellsten, M. (2002) Students in transition: needs and experience of international students in Australia. Paper presented at the $16^{\text {th }}$ Australian International Education Conference, Hobart, Tasmania.

Hellsten, M. and Prescott, A. (2004) Learning at university: the international students experience. International Education Journal, 5, (3), 344-351.

Holec, H. (1981). Autonomy and foreign language learning. Oxford: Pergamon. (First published [1979], Strasbourg: Council of Europe.)

Kenny, B. (1993) 'For More Autonomy'. System, 21(4), 431-442.

Knowles, M. (1984). The Adult Learner: A Neglected Species $\left(3^{\text {rd }}\right.$ ed.).Houston: Gulf Publishing. Knowles, M. S. (1980).

Legenhausen, L. (2003) Second language acquisition in an autonomous learning environment. In D. Little, J. Ridley and E. Ushioda (eds) Learner Autonomy in the Foreign Language Classroom: Teacher, Learner, Curriculum and Assessment (pp. 65_77). Dublin: Authentik.

Legenhausen, L. (1999) The emergence and use of grammat- ical structures in conversational interaction. In B. Mißler and U. Multhaup (eds) The Construction of Knowledge: Learner Autonomy and Related Issues in Foreign Language Learning (pp. 27_40). Tu” bingen: Stauffenburg.

Little, D. (1991). Learner autonomy 1: Definitions, issues and problems. Dublin: Authentik.

Littlewood, W. (1996). "Autonomy": An anatomy and a framework. System, 24(4), 427-435.

Little, D. (1999). Learner autonomy is more than a western cultural construct. In S. Cotterall \& D. Crabbe (Eds.), Learner autonomy in language learning: Defining the field and affecting change (p.11-18). New York: Frankfurt.

Littlewood, W. 1999. "Defining and Developing Autonomy in East Asian Contexts." AppliedLinguistics 20 (1), 71-94.

Littlewood, W. (2001). Students' attitudes to classroom English learning: a cross-cultural study. Language Teaching Research 5.1: 3-28.

Little, D. (2000). Learner autonomy and human interdependence: some theoretical and practical consequences of a social-interactive view of cognition, learning and language. In B. Sinclair, I. McGrath and T. Lamb (eds), Learner Autonomy, Teacher Autonomy: Future Directions, 15-23. Harlow: Longman/Pearson Education.

Mahdavinia, M., \& Nabatchi Ahmadi, L. (2011).portfolio assessment: A tool for self-directed learning at post-secondary level. In D. Gardner (Ed.), Fostering autonomy in language learning (pp. 76-90). Gaziantep: Zirve University.

Mulligan, D and Kirkpatrick, A. (2000) How much do they understand? Lecturers, students and comprehension. Higher Education Research and Development, 19, (3), 311-335.

Park, E. (2003). Learner autonomy in selected populations of East Asian graudate students whostudy at institutions in the United States. Doctoral dissertation, The Graduate School of Education and Human Development of the George Washington University.

Pennycook, A. (1997). Cultural alternatives and autonomy. In P. Beson \& P. Voller (Eds.), Autonomy and independace in language learning (pp. 35-53). New York: Longman.

Ponton, M. K. \& Hall, J. M. (2003). The relationship between postsecondary education and personal initiative for adult learners. Current Issues in Education, 6(17). Retrieved from http://cie.ed.asu.edu/volume6/number17

Riley, P. 1988. "The Ethnography of Autonomy." In A. Brookes and P. Grundy (Eds.), Individualization and Autonomy in Language Learning. London: Modern English Publications/The British Council.

Robertson, M., Line, M., Jones, S. and Thomas, S. (2000) International students, learning environments and perceptions: A case study using the Delphi technique. Higher Education Research and Development, 19, (1), 89-102.

Scharle, A. \& Szabó, A. (2000). Learner autonomy: A guide to develop learner responsibility. Cambridge: Cambridge University Press. 
Sedigheh shakib Kotamjani \& Habsah Hussin. (2017). Perception of challenges in writing academically: Iranian postgraduate students' perspectives. International Journal of Applied Linguistics \& English Literature. 6(4), 1-4. http://dx.doi.org/10.7575/aiac.ijalel.v.6n.4p.1

Smith, L. B. (2003). Learning to recognize objects. Psychological Science, 14,244-250.
Smith, R. C. (2008). Learner autonomy (Key concepts in ELT). ELT Journal, 62 (4),395-397.

Suharmanto. (2003). Learning autonomy: A way to improve English language teaching (ELT) in Indonesia. TEFLIN Journal, 14(1), 111-122.

Wong, J. K. (2004) Are the learning styles of Asian internationals culturally or contextually based? International Education Journal, 4, (4), 154-166. 